\title{
Ecological Diversity of Microbial Consortium Feces of Beef Cattle and Lignite Coal
}

\author{
Gina Chynthia Kamarudin Puteri', Roni Ridwan², Ellin Harlia ${ }^{1 *}$ \\ ${ }^{1}$ Faculty of Animal Husbandry, Padjadjaran University, Sumedang, Indonesia \\ ${ }^{2}$ Research Center For Biotechnology-Indonesian Institute of Sciences, Bogor, Indonesia
}

\section{ARTICLE INFO}

Article history:

Received October 28, 2018

Received in revised form January 20, 2020

Accepted February 17, 2020

\section{KEYWORDS:}

Feces of beef cattle,

Lignite Coal,

Waste,

Microbial,

Biogas

\begin{abstract}
Increasing energy demand is not alongside the availability of limited fossil fuels. Alternative and renewable energy sources are not only an option to overcome energy problems but also essential to minimize global warming. Another critical and promising renewable energy source is biomass-derived from livestock feces. Beef cattle feces contain a microorganism consortium that can be used as a starter with coal media to form biogas. Indonesia recently developed coal waste processing into renewable energy, such as biogas. This study aimed to overview the ecological diversity of microbial consortium of beef cattle feces, lignite coal waste, and a combination of livestock and lignite coal waste under mesophilic conditions. This research is an explorative method, the data obtained were analyzed descriptively. The process of formation was carried out anaerobically on a bottle containing the rumen fluid medium. The fermentation process lasted 42 days at $39^{\circ} \mathrm{C}$ of temperature. After that, the sample was electrophoresis, followed by nextgeneration sequencing (NGS) method. NGS data is processed with the MG-Rast website. This study demonstrates the ecological diversity of microbial consortium of beef cattle, lignite coal waste, and a combined consortium. The results showed ecological diversity in the form of taxonomy dominated by bacteria, eukaryotes, and archaea.
\end{abstract}

\section{Introduction}

Beef cattle feces is a waste that has not optimally used. If not managed properly, it will pollute the river environment is to increase Biochemical Oxygen Demand (BOD), Chemical Oxygen Demand (COD), and reduce dissolved oxygen (DO) and can cause greenhouse gases. Feces is a livestock waste that contains organic materials that can be converted into energy sources in biogas form (Olvera and Lopez-Lopez 2012; Pap and Maróti 2016). Facilitate biogas formation; beef cattle feces can be handled by culturing beef cattle feces consortium as biogas starter with lignite coal media. Microorganisms in feces come from the digestive tract of beef cattle such as Enterobacter. Bioaugmentation and biostimulation process can increase the amount of microorganism from feces beef cattle and coal more than $10^{10} \mathrm{CFU} /$ $\mathrm{ml}$ so that can be used as biogas starter.

\footnotetext{
* Corresponding Author

E-mail Address: ellin.harlia@unpad.ac.id
}

Biogas production can be carried out under different temperature process that affected biogas formation, such as compotition of microbial community and process stability (Stolze Y et al. 2015). The biogas formation process is divided into four continuous and simultaneous phases: hydrolysis, acidogenesis, acetogenesis, and methanogenesis. A community of complex anaerobic microbes performs all of those phase. The first three phases are carried out by bacteria, while the last phase is performed by archaea (Jünemanna et al. 2017). Biogas component is methane $\left(\mathrm{CH}_{4}\right)$, carbon dioxide $\left(\mathrm{CO}_{2}\right)$, nitrogen $\left(\mathrm{N}_{2}\right)$, hydrogen $\left(\mathrm{H}_{2}\right)$, oxygen $\left(\mathrm{O}_{2}\right)$, and hydrogen disulfide $\left(\mathrm{H}_{2} \mathrm{~S}\right)$ (Ohmiya K et al. 2005; Stolze Y et al. 2015).

Lignite coal is one type of coal that has calorific value $4,000-8,300 \mathrm{Btu} / \mathrm{lb}, 10-50 \%$ ash, $23-35 \%$ carbon, $0.4-1.0 \%$ sulfur, and $120 \pm 20 \mathrm{ppm}$ chlorine (Brian et al. 2008). Most of the low range of Indonesia's coal consists of hydrogen-rich component (Davis RC et al. 2007), so that has a good potential as substrate to utilize directly for biogenic $\mathrm{CH}_{4}$ generation from various starter such as beef cattle feces consortium, 
lignite coal waste, and combination of beef cattle feces consortium and lignite coal waste. Based on various starter used, the diversity of microbes form during incubation period for 42 days in $39^{\circ} \mathrm{C}$ can be observed. However, most of these microbes and their role in biogas production are not discover yet. A good understanding of the composition and activities of diverse microbial communities is very important to optimize the fermentation process. To find out the diversity of microorganisms in the sample, molecular methods are used. The molecular method used is Next Generation Sequencing (NGS) technology. NGSbased metagenomics explains the analysis of the genomic content of a whole microbial community. It provides insight into its structure and function, resulting in information about organisms that are not easily cultured (Jünemanna et al. 2017). NGS is the latest applied science technology tool. This tool has a great ability in produce DNA sequences throughout the genome of an organism. NGS technology can also quickly capture the variety and number of microorganisms from a genomic environment in the microbial community. Data generated through NGS is assisted by analysis using MG-Rast servers. The MG-Rast server analyzes each metagenome dataset involving a comparison of known sequence data. In this research, the biogas digester's microbial community with starter microbial beef cattle feces and microbial starter of coal were analyzed by applying the metagenomic approach. The results obtained were compared with taxonomic community profiles inferred from the biogas digester with a combined microbial starter from beef cattle and coal feces.

\section{Materials and Methods}

This study was explorative research, which consists of research conducted on the growth of biogas bacteria from a consortium of beef cattle feces, lignite coal waste and a mixture of a consortium of beef cattle feces, and lignite coal waste carried out in the laboratory scale. This study using molecular analysis with Next Generation Sequencing method as a tool to see the diversity of microorganisms. The results of data analysis from the NGS were analyzed using the MG-Rast data server. In this study, the data discussed is taxonomic data based on domain, phylum, class, and genus. The data will be analyzed descriptively. The material used for this research were beef cattle feces taken from teaching farm Padjadjaran University, lignite coal from Berau, East Kalimantan, Indonesia, and rumen fluid from Cikuda slaughterhouse, Jatinangor.

The research process is by in vitro culturing beef cattle consortium and anaerobic adaptation to serum bottles containing rumen media (Ogimoto and Imai 1981) for two weeks. After two weeks, a starter is ready used for biogas fermentation. Fermentation was carried out on three serum bottles (as digester) with three replications. The first serum bottle is filled with liquid media and a consortium of beef cattle feces, the second bottle is filled with liquid media, and lignite coal waste and the third serum bottle is filled with a combination of beef cattle feces consortium and new lignite coal waste. The use of starter consortium of beef cattle feces is used by $4 \%$ of $100 \mathrm{ml}$ of liquid media. The use of coal as much as $10 \%$ of $100 \mathrm{ml}$ of liquid media. Samples were incubated at $39^{\circ} \mathrm{C}$ for 42 days. Then DNA extraction was then carried out by electrophoresis and continued with the next generation sequencing (NGS) method. The NGS data obtained were processed with the MG-Rast website (De Francisci et al. 2015). After obtaining the results of data through MG-Rast, the data is analyzed descriptively.

\section{Results}

This study analyzed the diversity of biogas forming microorganisms from the consortium of beef cattle feces, lignite coal waste, and a mixture of beef cattle feces consortium and lignite coal waste.

Table 1 showed that based on domains, microorganisms detected were dominated by bacteria as follows $99.59 \%$ in the microbial consortium of beef

Table 1 . The NGS result based on domain

\begin{tabular}{llll}
\hline \multirow{2}{*}{ Taxonomy } & & \multicolumn{1}{c}{ Source } & \\
\cline { 2 - 4 } & $\begin{array}{l}\text { Beef cattle feces microbial } \\
\text { consortium }\end{array}$ & Lignite coal waste & $\begin{array}{l}\text { Beef cattle feces microbial } \\
\text { consortium and lignite coal }\end{array}$ \\
\hline & Bacteria $(98.89 \%)$ & Bacteria $(99.68 \%)$ & Bacteria $(98.57 \%)$ \\
Archaea $(1.34 \%)$ \\
Domain & Eukaryota $(1.05 \%)$ & Archaea $(0.18 \%)$ & Eukaryota $(0.09 \%)$ \\
& Archaea $(0.05 \%)$ & Eukaryota $(0.14 \%)$ & Unclassified sequences (0.00\%) \\
& Unclassified sequences (0.01\%) & & \\
\hline
\end{tabular}


cattle feces, $99.68 \%$ in lignite coal waste, and $98.57 \%$ in mixed feces of beef cattle and lignite coal waste.

Table 2 showed the analysis result on the phylum of samples. Based on phylum, the three samples were dominated by Firmicutes, as much as $72.58 \%$ in beef cattle feces consortium, $89.94 \%$ in lignite coal waste, and $97.65 \%$ in the mixture of beef cattle feces and lignite coal waste consortium.

Table 3 Showed the analysis result in class. In the sample of beef cattle feces consortium were dominated by Bacilli as much as $67.69 \%$ while in lignite coal waste and the mixture of beef cattle feces consortium and lignite coal waste was dominated by Clostridia as much as $47.55 \%$ and $70.96 \%$.

\section{Discussion}

The growth process of microorganisms influenced by environmental conditions, substrate, temperature, and $\mathrm{pH}$. The presence of microorganisms formed greatly influenced the biogas formation. Taxonomy on the three samples was obtained by using the MG-Rast server (Table 1). Table 1 showed that based on domains, microorganisms detected were dominated by bacteria

Table 2. The NGS result based on phylum

\begin{tabular}{|c|c|c|c|}
\hline \multirow[b]{2}{*}{ Taxonomy } & \multicolumn{3}{|c|}{ Source } \\
\hline & $\begin{array}{l}\text { Beef cattle feces microbial } \\
\text { consortium }\end{array}$ & Lignite coal waste & $\begin{array}{l}\text { Beef cattle feces microbial } \\
\text { consortium and lignite coal }\end{array}$ \\
\hline \multirow{15}{*}{ Phylum } & Firmicutes (72.58\%) & Firmicutes (89.49\%) & Firmicutes (97.65\%) \\
\hline & Synergistetes (22.57\%) & Synergistetes (5.58\%) & Euryarchaeota (1.35\%) \\
\hline & Arthropoda (1.10\%) & Proteobacteria (1.82\%) & Unclassified (derived \\
\hline & Proteobacteria (1.03\%) & Planctomycetes (1.69\%) & Bacteria) $(0.16 \%)$ \\
\hline & Cyanobacteria (0.096\%) & Verrucomicrobia (0.53\%) & Planctomycetes (0.15\%) \\
\hline & Unclassified (derived from & Unclassified (derived from & Tenericutes (0.12\%) \\
\hline & bacteria) $(0.78 \%)$ & bacteria) $(0.23 \%)$ & Proteobacteria (0.12\%) \\
\hline & Actinobacteria (0.34\%) & Euryarchaeota $(0.18 \%)$ & Elusimicrobia (0.09\%) \\
\hline & Bacteroidetes (0.24\%) & Bacteroidetes (0.18\%) & Actinobacteria (0.08\%) \\
\hline & Elusimicrobia (0.13\%) & Actinobacteria (0.15\%) & Bacteroidetes (0.06\%) \\
\hline & Lentisphaerae (0.13\%) & Arthropoda (0.11\%) & Arthropoda (0.06\%) \\
\hline & Euryarchaeota (0.06\%) & Lentisphaerae (0.06\%) & Verrucomicrobia (0.04\%) \\
\hline & Chloroflexi (0.04\%) & Streptophyta (0.03\%) & Acidobacteria (0.04\%) \\
\hline & Streptophyta $(0.04 \%)$ & Elusimicrobia $(0.00 \%)$ & Streptophyta (0.03\%) \\
\hline & $\begin{array}{l}\text { Unclassified (derived from } \\
\text { unclassified sequences) }\end{array}$ & Spirochaetes (0.00\%) & Synergistetes (0.03\%) \\
\hline
\end{tabular}

Table 3. The NGS result based on class

\begin{tabular}{|c|c|c|c|}
\hline \multirow[b]{2}{*}{ Taxonomy } & \multicolumn{3}{|c|}{ Source } \\
\hline & $\begin{array}{l}\text { Beef cattle feces microbial } \\
\text { consortium }\end{array}$ & Lignite coal waste & $\begin{array}{l}\text { Beef cattle feces microbial } \\
\text { consortium and lignite coal }\end{array}$ \\
\hline \multirow{16}{*}{ Class } & Bacilli (67.69\%) & Clostridia (47.55\%) & Clostridia $(70.96 \%)$ \\
\hline & Synnergistia (22.7\%) & Bacilli (42.18\%) & Bacilli (25.84\%) \\
\hline & Clostridia (3.18\%) & Synnergistia (5.68\%) & Negativicutes (1.87\%) \\
\hline & Negativicutes (1.54\%) & Deltaproteobacteria (1.82\%) & Unclassified (derived \\
\hline & Insecta $(1.11 \%)$ & Planctomycetacia (1.72\%) & Bacteria ) $(0.20 \%)$ \\
\hline & Unclassifies (derived from & Unclassified (derived from & Planctomycetacia $(0.18 \%)$ \\
\hline & Cyanobacteria (0.96\%) & bacteria ) $(0.24 \%)$ & Mollicutes (0.15\%) \\
\hline & Deltaproteobacteria (0.87\%) & Actinobacteria (0.16\%) & Elusimicrobia (0.11\%) \\
\hline & Unclassified (derived from & Bacteroidia (0.15\%) & Actinobacteria $(0.10 \%)$ \\
\hline & bacteria ) $(0.79 \%)$ & Negativicutes (0.11\%) & Gammaproteobacteria (0.10\%) \\
\hline & Actinobacteria (0.34\%) & Insecta $(0.11 \%)$ & Insecta $(0.08 \%)$ \\
\hline & Bacteroidia $(0.16 \%)$ & Verrucomicrobiae (0.07\%) & Bacterioidia (0.07\%) \\
\hline & Elusimicrobia (0.13\%) & Unclassified (derived from & Methanobacteria (0.07\%) \\
\hline & Unclassified (derived from & Lentisphaerae) (0.06\%) & Verrucomicrobiae (0.05\%) \\
\hline & Lentisphaerae) (0.10\%) & Spartobacteria (0.03\%) & Solibacteres (0.04\%) \\
\hline & Flavobacteria $(0.07 \%)$ & Liliopsida $(0.03 \%)$ & \\
\hline
\end{tabular}


as follows $99.59 \%$ in the microbial consortium of beef cattle feces, $99.68 \%$ in lignite coal waste, and $98.57 \%$ in mixed feces of beef cattle and lignite coal waste. The presence of bacteria in the process of biogas formation was essential, beginning with the hydrolysis process as the first step in the degradation of complex organic substrates into a simple substrate. During hydrolysis, complex biopolymers such as cellulose, starch, proteins, and lipids were degraded to oligo and monomers by hydrolytic bacteria from the Bacteroidetes phylum and Firmicutes (Drake et al. 2002).

Table 2 showed the analysis result on the phylum of samples. Based on phylum, the three samples were dominated by Firmicutes, as much as $72.58 \%$ in beef cattle feces consortium, $89.94 \%$ in lignite coal waste, and $97.65 \%$ in the mixture of beef cattle feces and lignite coal waste consortium. Phylum Firmicutes had an essentialrole in the hydrolysis of biomass and in the fermentation process. Firmicutes were very important in cellulose degradation by the microbial community of biogas (Jaenicke et al. 2011). Firmicutes included all gram-positive bacteria. Firmicutes consisted of 26 families and 223 genera (Gibbons and Murray 1978). Forms of phylum Firmicutes cells were round, or straight, curved and helical or filaments with or without flagella and with heat-resistant or endospores (Bergey and Boone 2009). It could live under aerobic, facultative, or anaerobic conditions. Some members of the Firmicutes were thermophilic and or halophil bacteria. Most of Firmicutes were anoxygenic chemo-organotrophs. Most grew at neutral $\mathrm{pH}$, while some were acidophiles or alkalyphilic (Bergey and Boone 2009).

The results of the class were slightly different (Table 3 ). In the sample of beef cattle feces consortium were dominated by Bacilli as much as $67.69 \%$ while in lignite coal waste and the mixture of beef cattle feces consortium and lignite coal waste were dominated by Clostridia as much as $47.55 \%$ and $70.96 \%$, respectively. Bacilli and Clostridia classes were important bacteria that contribute to the decomposition of organic substrates. The results showed the importance of microbial communities metabolizing hydrogen in biogas formation (Wirth et al. 2012). The Bacilli class was generally grampositive, and some grow under facultative anaerobic conditions (Bergey and Boone 2009). The Clostridia class contained gram-positive bacteria and negative gram stains. The class consisted of order Clostridiales, Halanaerobiales, and Thermoanaerobacterales (Bergey and Boone 2009).
In mixed sources of beef cattle feces consortium and lignite coal waste can be seen aa a class of 0.07\% Methanobacteria. Methanobacteria includes one anaerobic non-halophilic and thermophilic archaebacteria. The special characteristic of methanogen groups is autotrophic or heterotrophic, the energy produced from oxidation of hydrogen, forms acetate with methane formation. Cells form balls, rods, and spirals, and are gram negative or positive.

In the MG-Rast analysis based on the genus, it showed that microbial consortium of beef cattle feces dominated by $64.34 \%$ Bacillus, followed by Pyramidobacter 25.28\%, unclassified (derived from Bacteria) 2.48\%, Syntrphomonas 1.35\%, Desulvovibrio $0.97 \%$, Clostridium $0.86 \%$ (Figure 1). Data based on the genus indicated that bacteria formed during 42 days of fermentation fluctuated, the dominance of bacteria presented in the hydrolysis stage. The bacteria contained in the hydrolysis stage were Bacillus and Clostridium (Wirth et al. 2012). This was in accordance with (Bryant and Burkey 1976) that microbes that had a role in the hydrolysis process were Clostridium aceticum, Bacteriodes ruminicola, Bifidobacterium sp., E. coli, Enterobacter sp., Desulfurvibrio sp., Pseudomonas sp., Flavobacterium alkaligenes, and Aerobacter. Observations based on the genus found Lactobacillus and syntrophomonas bacteria, which showed the acidogenesis process. Similarly, (Bryant and Burkey 1976) suggested that microbes that had a role in the acetogenesis were Syntrophobacter sp. and Pelotomaculum sp.

Based on MG-Rast result, the genus found in coal waste dominated by Clostridium $51.28 \%$, followed with Bacillus 35.29\%, Pyramidobacter 6.13\%, Desulfovibrio $2.04 \%$, Planctomyces $1.38 \%$, and Syntrophomonas $0.56 \%$ (Figure 1). This was consistent with (Susilawati 2015), who stated that bacterial species from the Clostridium genus were geopolymer hydrolyzers in biogenic Coal Bed Methane (CBM) reservoirs. This showed that after applying the treatment and growing bacteria in waste, it still showed biogenic coal. The study results on beef cattle feces and lignite coal consortium were almost the same because the hydrolysis stage bacteria still dominated it.

Genus found in mixture of beef cattle feces consortium and lignite coal, namely Clostridium (72.37\%), Bacillus (31.67\%), Lysinibacillus (0.89\%), Thermosinus (0.63\%), Caldicellulosiruptor (0.39\%), and Lactobacillus (0.29\%). Clostridium genus in the 


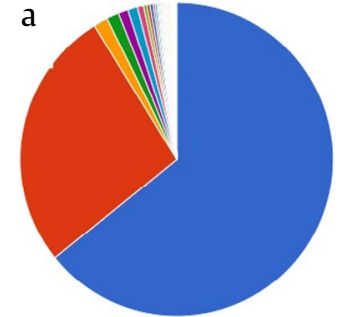

Bacillus - 227.174 (64.21\%)

- Pyramidobacter - 95,648 (27.03\%)

Syntrophomonas - 5,108 (1.44\%)

- Coptotermes - 4,660 (1.23\%)

- Desulfovibrio - 3,624(1.02\%)

unclassified (derived from bacteria) - 3,326 (0.94\%)

- Clostridium - 2,314 (0.65\%)

- Acidaminococcus - 1,385 (0.39\%)

- Phascolarctobacterium - 1.084 (0.31\%)

- Lactobacillus - 1,074 (0.30\%)

Halothermothrix - 735 (0.21\%)

Elusimicrobium - 563 (0.16\%)

Lysinibacillus - 471 (0.13\%)

- Victivallis - 432 (0.16\%)

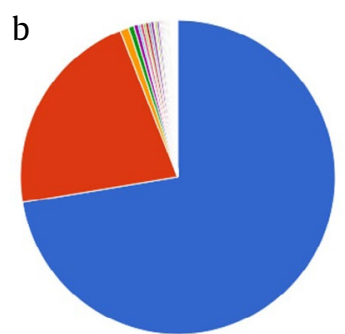

- Clostridium - 263,884 (72.37\%)

- Bacillus - 79,014 (21.67\%)

Lysinibacillus - 3,252 (0.89\%)

Thermosinus - 2,311 (0.63\%)

- Caldicellulosiruptor - 1,405 (0.39\%)

- Lactobacillus - 1,060 (0.29\%)

Pelotomaculum-1,004 (0.28\%)

Paenibacillus - 1,000 (0.27\%)

Desulfotomaculum - 995 (0.27\%)

Tissierella - $918(0.25 \%)$

unclassified (derived from bacteria) - $861(0.24 \%)$

Syntrophomonas - $758(0.21 \%)$

Candidatus Phytoplasma - 626 (0.17\%)

Rhodopirellula - $574(0.16 \%)$
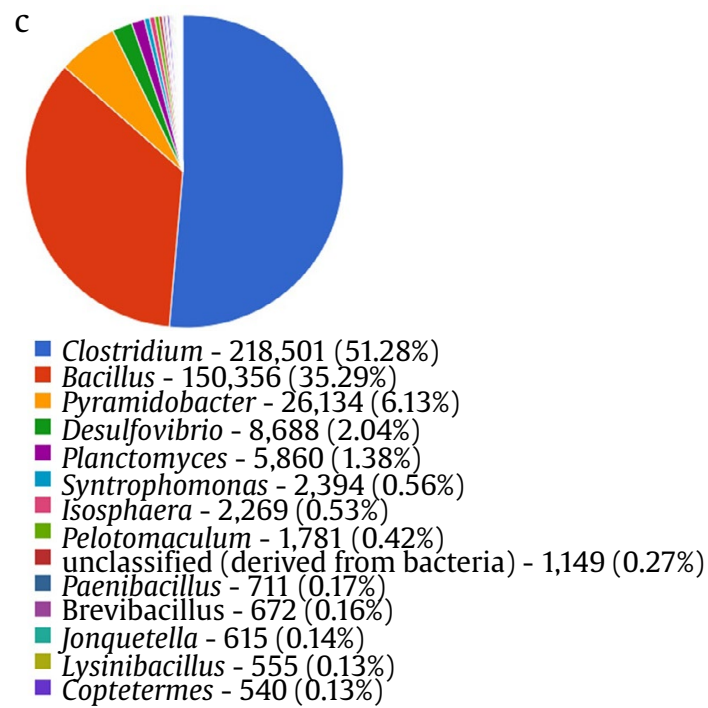

Figure 1. The NGS result based on genus. (a) The MG-Rast result on beef cattle feces consortium, (b) The MG-Rast result on lignite coal waste, (c) The MG-Rast result on mixture of beef cattle feces consortium and lignite coal waste It can be seen that there was data fluctuation particularly in starter from coal waste microbes

early stages of growth was generally gram positive, although in some species gram negative. When motile, it was commonly Peritrichous, the majority of species were oval or round endospores, which inflated cells. It generally produced a mixture of organic acids and alcohol from carbohydrates or peptones. It could metabolize carbohydrates, alcohols, amino acids, and organic compounds (Bergey and Boone 2009).

Genus dominated in lignite coal waste, and a mixture of beef cattle feces and lignite coal were Clostridium and Bacillus, while in beef cattle feces consortium was Bacillus. Genus Clostridium and
Bacillus were identified most dominant under mesophilic conditions.

\section{Conclusion}

The results of the metagenomic NGS data processed through MG-Rast can show ecological diversity of mesophilic temperature from the microbial consortium of beef cattle feces, microbes from coal and mixed starters which are complex starters, difficult to culture but can symbiosis to produce biogas according to the role of each microbe 
in every phase. The exogenous anaerobic microbes used in this study and the original microbes are basically the same, at least at the phylum level.

\section{Acknowledgements}

Credits are given to Academic Leadership Grant (ALG) Universitas Padjadjaran that has funded this research.

\section{References}

Bergey DH, Boone DR. 2009. Bergey's Manual of Systematic Bacteriology. Vol.3, 2nd ed. New York:Springer ScienceBusiness Media.

Bryant MP, Burkey LA. 1976. Cultural methods and some characteristics of some of the more mumerous group of bacteria in the bovine rumen.J Diary Sci 36:205-217.

Brian H et al. 2008. Coal Characteristics. The Energy Center at Discovery Park. Indiana: Purdue University.

Davis RC et al. 2007. The petroleum potential of tertiary coals from Western Indonesia: relationship to mire type and sequence stratigraphic setting. Int J Coal Geol 70:35-52.

De Francisci D et al. 2015. Microbial diversity and dynamicity of biogas reactors due to radical changes of feedstock composition. Bioresource Technology 176:56-64.

Drake Het al. 2002. Ecological consequences of the phylogenetic and physiological diversities of acetogens. Antonie Van Leeuwenhoek 81:203-213.

Gibbons NE, Murray RGE. 1978. Proposals concerning the higher taxa of bacteria. Int J Syst Bacteriol 28:1-6.
Jaenicke S et al. 2011 .Comparative and joint analysis of two metagenomic datasets from a biogas fermenter obtained by 454-pyrosequencing. PLoS One 6:e14519.

Jünemanna $S$ et al. 2017. Bioinformatics for NGS-based metagenomics and the application to biogas research. Journal of Biotechnology 261:10-23.

Ogimoto K, Imai S. 1981. Atlas of Rumen Microbiology. Tokyo:JSSP.

Ohmiya Ket al. 2005. Anaerobic bacterial degradation for the effective utilization of biomass. Biotechnol Bioprocess Eng 10:482-493.

Olvera J, Lopez-Lopez A. 2012. Biogas Production from Anaerobic Treatment of Agro-Industrial Wastewater. Enviromental Technology Unit. Centre of Research and Assistance in Technology and Design of The State of Jalisco (CIATEJ). Mexico. 91-112.

Pap B, Maróti G. 2016. Diversity of microbial communities in biogas reactors. Current Biochemical Engineering 3:177-187.

Stolze Y et al. 2015. Comparative metagenomics of biogasproducing microbial communities from productionscale biogas plants operating under wet or dry fermentation conditions. Biotechnology for Biofuels 8:14. DOI:10.1186/s13068-014-0193-8

Susilawati SSR. 2015. Biogenic Methane in Indonesian Coal: Assessing the Potential using Culture Enrichment, Molecular Phylogenetic and Isotopic Analysis [Thesis]. Queensland, Australia : School of Earth Sciences The University of Queensland.

Wirth R et al. 2012. Characterization of a biogas-producing microbial community by short-read next generation DNA sequencing. Biotechnology for Biofuels 5:41. DOI:10.1186/1754-6834-5-41 